\title{
CFD Analysis of Monolithic Heat Exchanger by Using Various Ceramic Materials
}

\author{
S.Elangovan ${ }^{1}$, M.Sundararaj ${ }^{2}$, E.Mahavishnu ${ }^{3}$ \\ ${ }_{1,2}$ Professor, Department of Aeronautical Engineering, Bharath Institute of Higher Education and Research, \\ Chennai. \\ ${ }^{3}$ Assistant Professor, Department of Aeronautical Engineering, Bharath Institute of Higher Education and Research, \\ Chennai.
}

Article History: Received: 11 January 2021; Accepted: 27 February 2021; Published online: 5 April 2021

ABSTRACT:The main objective of this paper is to increase the heat exchange rate in the monolithic heat exchanger by changing the air passage shape and materials; here we used circular, hexagonal, oval shape for air passage and $\mathrm{Al}_{2} \mathrm{O}_{3}, \mathrm{SiC} \mathrm{CrCO}_{3}$ ceramic materials for our research work. The heat flow rate is analyzed in CFD fluent software and model in done in CATIA software.

.Key words: Monolithic heat exchanger, $\mathrm{Al}_{2} \mathrm{O}_{3}, \mathrm{Sic}, \mathrm{CrCO}_{3}, \mathrm{CFD}, \mathrm{ANSYS}$

\section{Introduction:}

Heat exchanger which is used to transfer the thermal energy from one medium to another medium there are three ways is available to transfer the heat that are conduction, convection and radiation. In this research work we are going to take conduction and radiation method for our application.

In this research the exchanger device made up of different type of ceramic materials for conduction process, various shapes of air passages used for radiation process, the ultimate aim of this project to increase the heat transfer rate while using different type of materials and air passage shape. Here we used $\mathrm{Al}_{2} \mathrm{O}_{3}, \mathrm{SiC}_{2} \mathrm{CrCO}_{3}$ material for our research each material having own heat transfer rate while analyzing the these transfer rate we can able to identify which material is most efficient, in addition that the transfer rate is varying with respect air passage shape also so here we used circular, hexagonal, oval shape.

Present work we tried different air passage, material combination to get the better performance, CFD fluent is used for analyzing process and CATIA is used for design the model. Finally while comparing the fluent result we can get which combination gives better heat transfer rate.

Modeling of Monolithic Heat Exchangers:

The modeling of the monolithic heat exchanger is the making a cross fluid flows in a normal ceramic blocks the sections are considered as a place of circular holes, oval shape holes and Hexagonal shape holes the shape of the heat exchangers are modeled by using CATIA Software by using the commends of Pad and Pocket and assembley

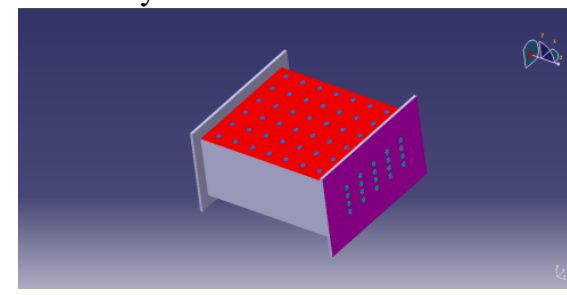

3D Model

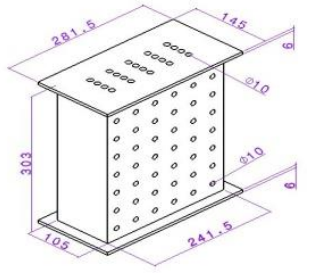

2D Model

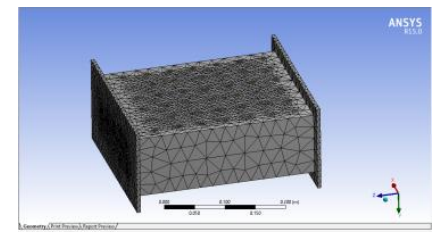

Mesh Model

Fig No: 1 Circular air passage monolithic heat exchanger

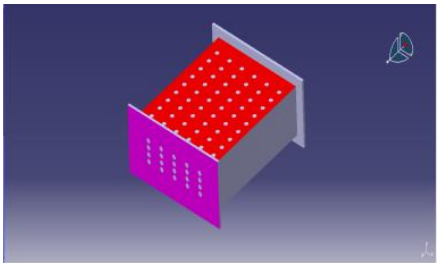

3D Model

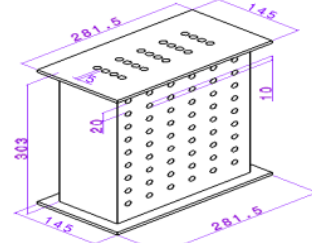

2D Model

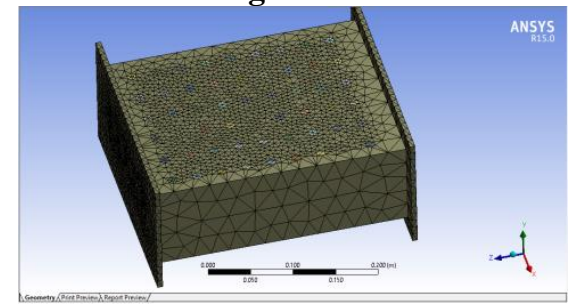

Mesh Model

Fig No: 2 Hexagonal air passage monolithic heat exchanger 


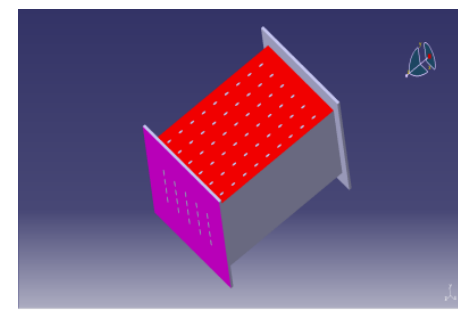

3D Model

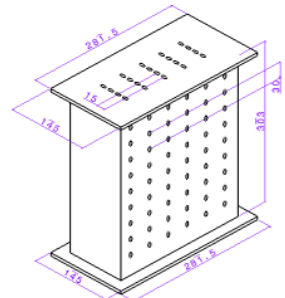

2D Model

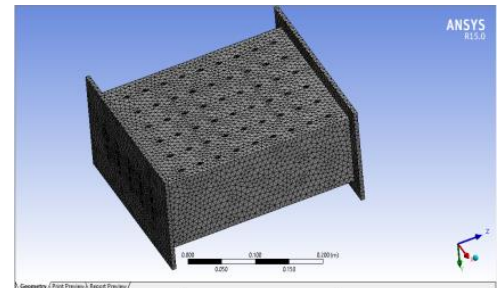

Mesh Model

Fig No: 3 Oval air passage monolithic heat exchanger

\section{CFD Simulation:}

The CFD Simulation of the Monolithic heat exchanger can be done in ANSYS Fluent Software the heat transfer analysis was done by using energy equation formulation in the model the K-Epsilon turbulence equation is used to find the turbulent flow in the heat transfer functions, the boundary conditions of Cold air inlet is $25^{\circ} \mathrm{C}$ and Hot air inlet is $1000^{\circ} \mathrm{C}$, and getting the contours of temperature difference of the heat exchanger with various materials

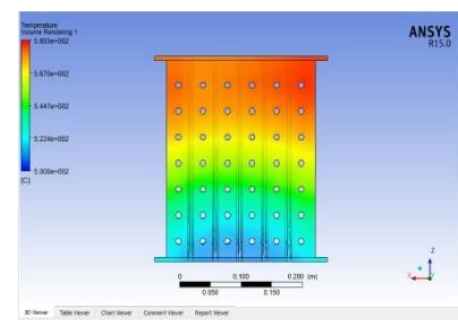

(A)Circular

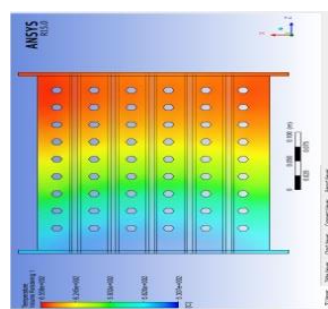

(B) Hexagonal
(C) Oval

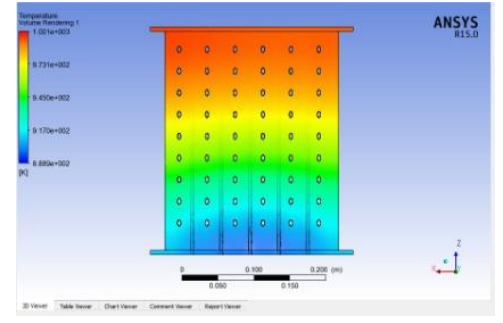

Fig No: $4 \mathrm{Al}_{2} \mathrm{O}_{3}$ Ceramic Monolithic Heat Exchanger

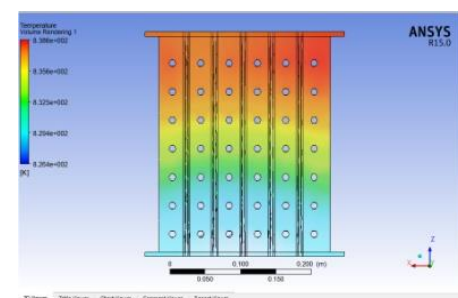

(A)Circular

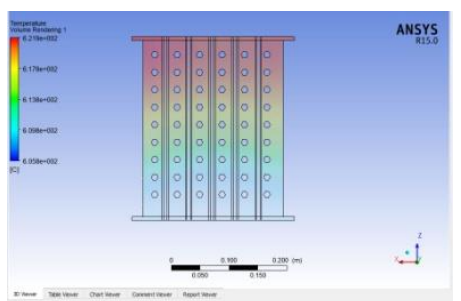

(B) Hexagonal

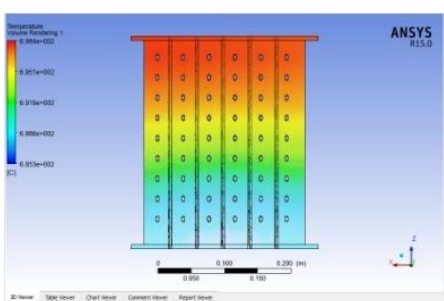

(C) Oval

Fig No: $5 \mathrm{CrCO}_{3}$ Ceramic Monolithic Heat Exchanger

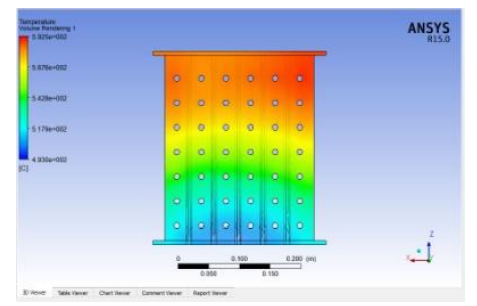

(A)Circular

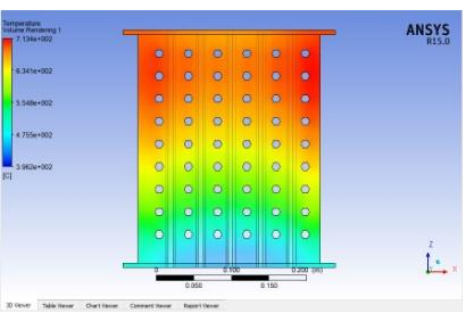

(B) Hexagonal

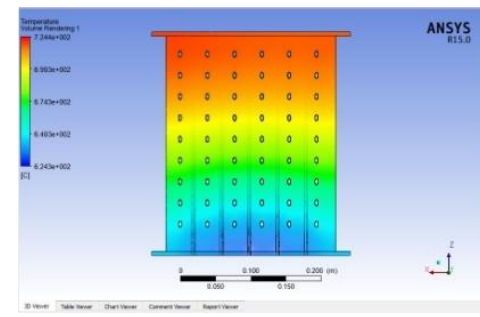

(C) Oval

Fig No: 6 SiC Ceramic Monolithic Heat Exchanger 


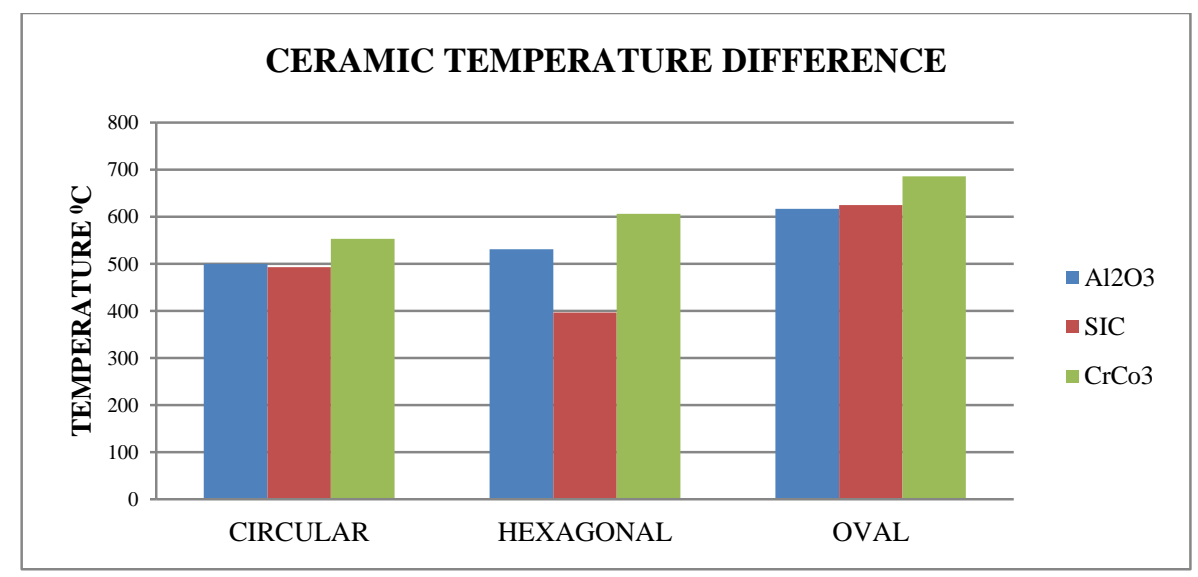

Fig No: 7 Comparison of temperature difference with varies ceramic materials and varies shape

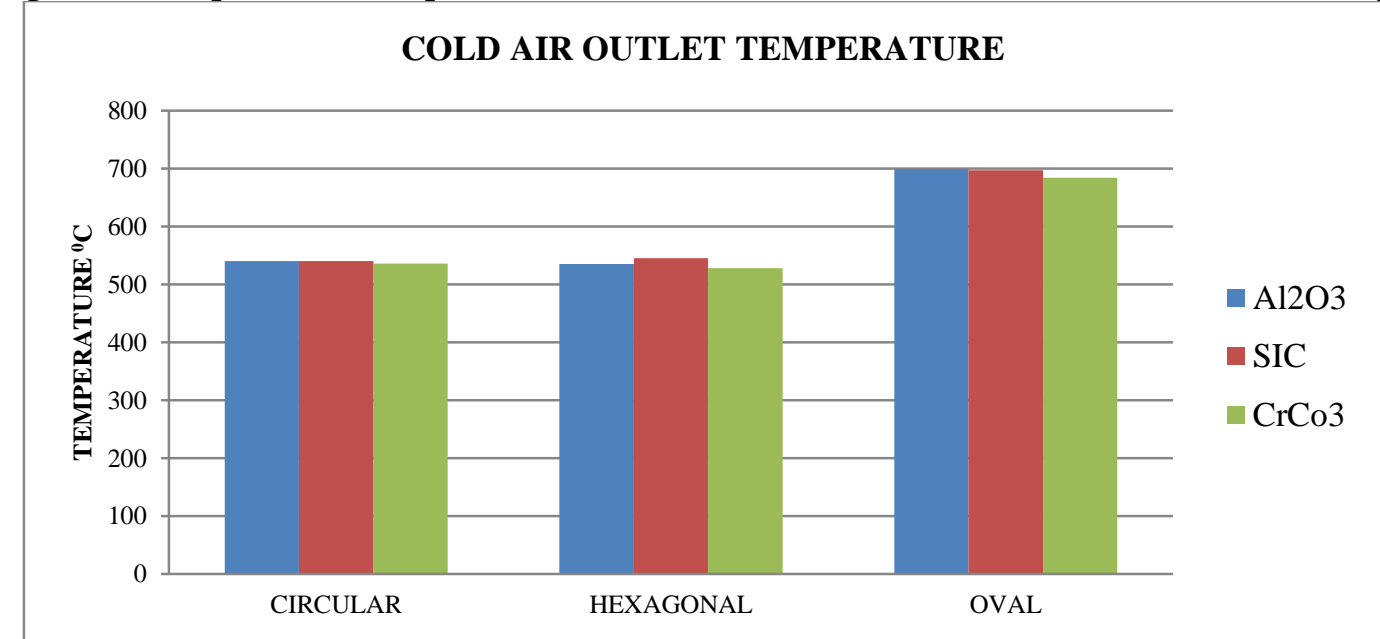

Fig No: 8 Comparison of cold air outlet temperature difference with varies ceramic materials and varies shape

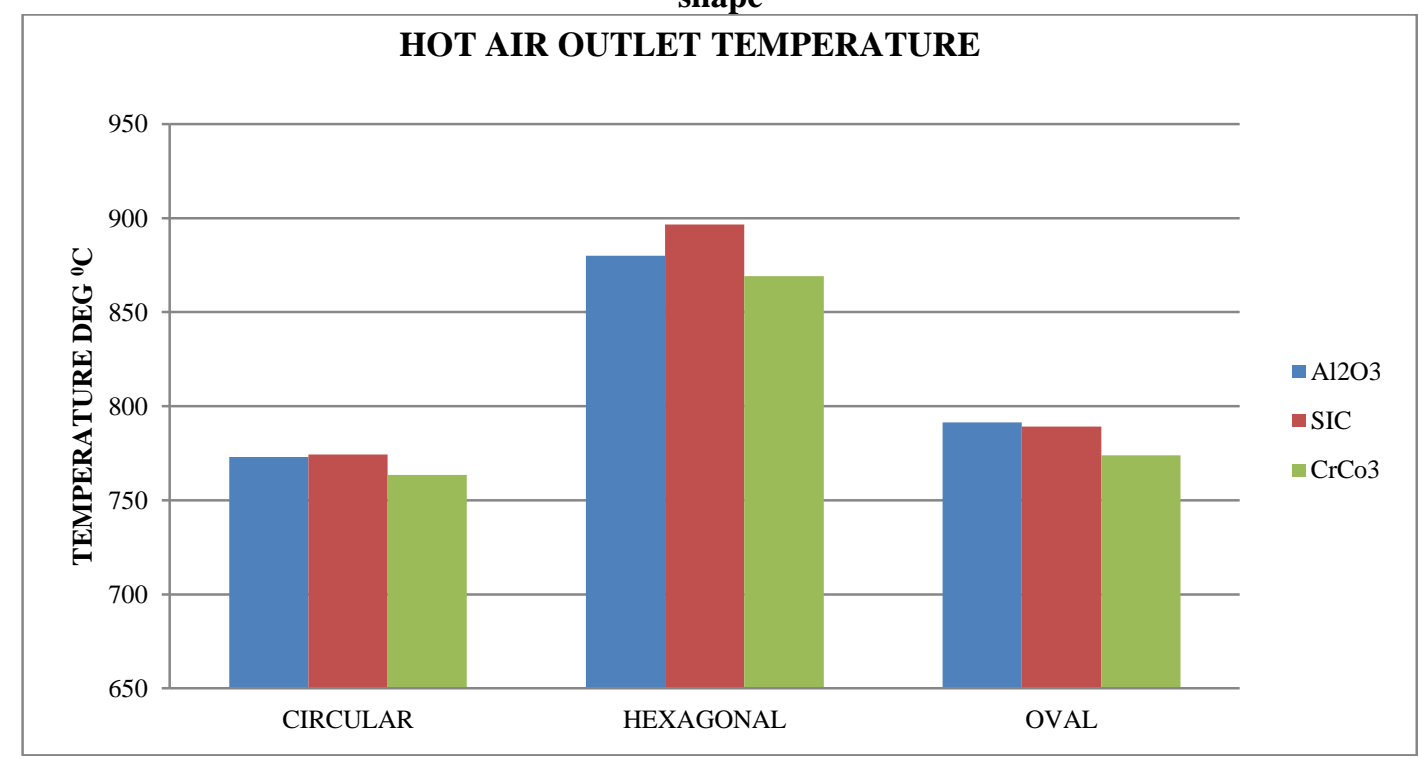

Fig No: 9 Comparison of hot air outlet temperature difference with varies ceramic materials and varies shape 


\section{Conclusion:}

The analysis of monolithic heat exchanger was done in CFD Methodology by using ANSYS Fluent Software; Circular, Hexagonal, Oval three different air passage shapes are created by using CATIA Software, from the heat transfer analysis oval shape heat exchangers will create the very level of the temperature difference in the hot air side for the $\mathrm{CrCO}_{3}$ ceramic heat exchangers so the analysis conclude with Oval shape air passage and $\mathrm{CrCO}_{3}$ ceramic material is suitable for the monolithic heat exchanger

\section{References}

1. Kays, W. M. and Crawford, M. E., 1980, Convective heat and mass transfer, McGraw-Hill, New York

2. Stephan, K. and Preußer, P., 1979, Wärmeübergang und maximaleWärmestromdichtebeimbehältersiedenbinärer und ternärerflüssigkeitsgemische, Chem. Ing. 51 p. 37 https://doi.org/10.1002/cite.330510112

3. Mills, A. F., 2003, Basic Heat and Mass Transfer, 2nd ed., Prentice Hall, New Jersey, p. 920

4. Yun, J. W. and Yun, J. Y., 1995, Numerical study on the characteristics of flow and heat transfer in finned tube heat exchanger, Journal of SAREK, pp. 74-79

5. Shah, R. K. and London, A. L., 1978, Laminar flow forced convection in duct, Suppl. 1, Adv. Heat Transfer

6. Mills, A. F., 2003, Basic Heat and Mass Transfer, 2nd ed., Prentice Hall, New Jersey, pp. 687-689 